\title{
Activation of p38 MAPK and/or JNK contributes to increased levels of VEGF secretion in human malignant glioma cells
}

\author{
YOSHIKAZU YOSHINO, MASARU AOYAGI, MASASHI TAMAKI, \\ LIAN DUAN, TAKASHI MORIMOTO and KIKUO OHNO
}

\author{
Department of Neurosurgery, Graduate School, Tokyo Medical and Dental University, Tokyo 113-8519, Japan
}

Received March 8, 2006; Accepted May 11, 2006

\begin{abstract}
Malignant gliomas are typically angiogenic and secrete high levels of VEGF. Hypoxia has been identified as an important regulator of VEGF. However, malignant gliomas express high levels of VEGF in both hypoxic perinecrotic and vital tumor areas. In this study, we examined intracellular signaling pathways involved in the secretion of VEGF in glioma cells under normoxic conditions. Human malignant glioma cell lines, T98G, U373MG, U87MG, and A172, and human fetal lung fibroblasts (HFL) were cultured both with and without IL-1ß under normoxic conditions. VEGF, IL-1, IL-6, and TNF- $\alpha$ were measured with ELISA. VEGF mRNA levels were estimated by RT-PCR. Inhibitors of COX-2, MAPK, and phosphatidyl inositol 3-kinase (PI3-K), and blocking antibodies to TGF- $\beta$ II and TNF- $\alpha$, or IL-1 receptor antagonist, were used to examine their effects on VEGF secretion. Phosphorylation of MAPK was examined by immunoblotting. The basal levels of VEGF secretion were significantly higher in U87MG, U373MG, and T98G, than HFL. IL-1B significantly stimulated VEGF secretion in these glioma cells. Inhibitors of p38 MAPK and/or JNK significantly suppressed VEGF secretion both in the presence and absence of IL-1ß, while inhibitors of COX-2, ERK1/2, and PI3-K did not. Constitutive phosphorylation of p38 MAPK and JNK was observed in these glioma cells. The levels of IL-1ß in U87MG were significantly higher than in other glioma cell lines, and IL-1 receptor antagonist suppressed basal secretion of VEGF from U87MG. In conclusion, p38 MAPK and JNK pathways play an important role in VEGF secretion from malignant glioma cells under normoxic conditions, possibly contributing to VEGF-induced angiogenesis in malignant gliomas at vital tumor areas where there is no hypoxia.
\end{abstract}

Correspondence to: Dr Yoshikazu Yoshino, Department of Neurosurgery, Graduate School, Tokyo Medical and Dental University, 1-5-45 Yushima, Bunkyo-ku, Tokyo 113-8519, Japan

E-mail: aoyagi.nsrg@tmd.ac.jp yyoshino@tdmc.hosp.go.jp

Key words: VEGF, malignant gliomas, p38 MAPK, JNK

\section{Introduction}

Malignant gliomas are the most common primary tumors in the brain. Despite multimodal therapy, the prognosis of patients with glioblastomas remains poor, with a median survival time of 12-18 months $(1,2)$. Malignant gliomas are typically angiogenic and characteristically exhibit endothelial cell hyperplasia $(3,4)$. Several angiogenic factors have been demonstrated in human gliomas. VEGF is one of the key angiogenic factors involved in the growth and malignant progression of tumors. VEGF has been shown to play a major angiogenic role in glioblastomas $(5,6)$. The levels of VEGF protein and the degree of mRNA expression in gliomas correlate with tumor grades and are most intense in glioblastomas (7). Numerous studies in animal models have shown that inhibiting VEGF function using neutral antibodies, dominant-negative VEGF receptor mutants, receptor antagonists, and antisense constructs inhibits growth of gliomas in vivo and causes regression of blood vessels (8-11).

Hypoxia has been well characterized as one of the pivotal regulators of VEGF expression. Glioblastomas express high levels of VEGF in the hypoxic regions of tumors, which are generally located near necrotic areas (7). VEGF is apparently induced under hypoxic conditions by transcription of VEGF mRNA via binding of either the hypoxia-inducible transcription factor (HIF-1) or AP-1 to a binding site located in the VEGF promoter $(9,12,13)$. However, glioblastoma cells have been shown to secrete and express persistently high levels of VEGF protein and VEGF mRNA even under normoxic conditions (14). Elevated levels of VEGF protein or mRNA expression has also been detected at the extreme periphery of some tumors in tissues where there is no evidence for hypoxia (7). These observations under normoxic conditions suggest that there exists a mechanism for activation of the VEGF gene in glioblastomas different from that postulated for hypoxia-induced activation of the VEGF gene.

VEGF expression in tumor cells is also regulated by many growth factors and cytokines, such as b-FGF, PDGF, TNF- $\alpha$, hepatocyte growth factor/scatter factor, TGF- 3 , EGF, IL-6, and IL-1ß (15-20). Recent studies have indicated that intracellular signal transduction mechanisms are involved in VEGF expression in malignant tumors. Several studies have shown that the phosphatidyl inositol 3-kinase (PI3-K)/Akt pathway mediates hypoxia-induced VEGF expression in rastransformed cells $(21,22)$. Other lines of evidence suggest that COX-2 mediates VEGF production in vitro and in vivo 
$(23,24)$. The major role of COX-2 in angiogenesis is thought to be the triggering of the synthesis of prostanoids, such as prostaglandin E2, which then stimulate the expression of proangiogenic factors (24). COX-2 is highly up-regulated in glioblastomas and levels of COX-2 correlate with VEGF protein levels (25-27). MAPKs, a family of serine/threonine kinases activated by dual phosphorylation of threonine and tyrosine within a Thr-X-Tyr motif (28), play a key role in the transcriptional and post-transcriptional regulation of VEGF $(29,30)$. In mammalian cells, three subgroups of MAPK have been detected, including ERK, JNK, and p38 MAPK (31). Ras triggers the activation of the ERK1/2 MAPK pathway to enhance VEGF transcription via AP-1 (29). IL-1 is one of the most potent inducers of VEGF among various cytokines and growth factors, and the activation of p38 MAPK is important for IL-1-induced VEGF production $(20,28)$. In the present study, we examined cultured human glioma cell lines for the production of VEGF stimulated with and without IL-1ß. Three of four glioma cell lines secrete high levels of VEGF protein in the culture medium even under steady-state and normoxic conditions. Our results indicate that p38 MAPK and/or JNK, but not COX-2 or ERK1/2, contribute to the increased levels of basal secretion of VEGF observed in these glioma cell lines.

\section{Materials and methods}

Materials. Human recombinant IL-1ß was a generous gift from Otsuka Pharmaceutical Co. (Tokushima, Japan). SB203580, a p38 MAPK-specific inhibitor, and PD98059, an ERK inhibitor, were obtained from Calbiochem (San Diego, CA). SP600125, a JNK inhibitor, was obtained from BIOMOL (Plymouth Meeting, PA). Actinomycin D and indomethacin were obtained from Sigma (St. Louis, MO). NS-398, a selective COX-2 inhibitor, and Wortmannin, a PI3-K-specific inhibitor were obtained from Calbiochem. The IL-1 receptor antagonist, TNF receptor antibody, and TGFß-II receptor antibody were all obtained from R\&D Systems (Minneapolis, MN).

Cell culture. Human malignant glioma cell lines T98G and A172 were obtained from the Japanese Cancer Research Resources Bank. Human malignant glioma cell lines U373MG and U87MG were obtained from the American Type Culture Collection. Human fetal lung fibroblasts were established as described previously (32). Cells were maintained in MEM (Life Technologies, Grand Island, NY) supplemented with 10\% FBS (Biocell, 6201B304, Carson, CA) under a 5\% $\mathrm{CO}_{2}$ - air mixture at $37^{\circ} \mathrm{C}$. The number of cells were counted with a Coulter counter (Industrial D, Coulter Corporation, Luton, UK). Mycoplasma assays were carried out using DNA fluorocytometry, and the cultures were found to be free from contamination.

Immunoassay for VEGF, $P G E_{2}, I L-1 \alpha$ and $\beta, I L-6$, and TNF- $\alpha$. Subconfluent cultured cells were washed with MEM containing $0.5 \%$ FBS. The medium was replaced with fresh MEM containing $0.5 \%$ FBS both with and without IL- $1 \beta$ (500 units/ml, $1.5 \mathrm{nM}$ ) or other reagents. Cells were incubated for $48 \mathrm{~h}$ at $37^{\circ} \mathrm{C}$, and the medium was collected. The concentrations of VEGF, IL- 6 , and $\mathrm{PGE}_{2}$ secreted into the medium were measured with ELISA kits for human VEGF, IL-6 (R\&D Systems) or an EIA kit for human $\mathrm{PGE}_{2}$ (Cayman Chemical). The concentrations of IL- $1 \alpha$, IL- $1 \beta$, and TNF- $\alpha$ in the culture medium and in cell extracts were measured with ELISA kits for human IL- $1 \alpha$, IL-1 1 , and TNF- $\alpha$ (R\&D Systems).

Actinomycin D $(100 \mathrm{ng} / \mathrm{ml})$, indomethacin $(1 \mu \mathrm{g} / \mathrm{ml})$, NS-398 $(1 \mu \mathrm{M})$, SB-203580 (1-5 $\mu \mathrm{M})$, SP-600125 (0.1-5 $\mu \mathrm{M})$, PD-98059 $(10 \mu \mathrm{M})$, and Wortmannin $(100 \mathrm{nM})$ were added to the cultures as VEGF production inhibitors. The inhibitor dosages used in this study were determined after preliminary experiments. IL-1 receptor antagonist $(100 \mathrm{ng} / \mathrm{ml})$ and the blocking antibodies to TNF-I receptors $(10 \mu \mathrm{g} / \mathrm{ml})$ and TGFß-II receptors $(20 \mu \mathrm{g} / \mathrm{ml})$ were used to compete with their respective ligands.

Western blot analysis. Subconfluent cultures were arrested in MEM containing $0.5 \% \mathrm{FBS}$ at $37^{\circ} \mathrm{C}$ for $24 \mathrm{~h}$ and then incubated for $30 \mathrm{~min}$ both with and without IL-1ß (500 units/ml). Cells were extracted by SDS sample buffer, sonicated, and then boiled for $5 \mathrm{~min}$. Equal amounts of protein were loaded onto $12.5 \%$ SDS-polyacrylamide gels and were transferred to Immobilon-P membranes (Millipore, Tokyo, Japan). The membranes were incubated with rabbit polyclonal antibodies to phospho- or non-phospho-p38 MAPK or phospho- or non-phospho-JNK antibodies (Cell Signaling, Beverly, MA). For the detection of COX-1 and COX-2, cells were incubated for $16 \mathrm{~h}$ both with and without IL-1ß. The cell extracts were run on SDS gels and were transferred to Immobilon-P membranes. The membranes were incubated with goat polyclonal antibodies to COX-1 or COX-2 (Santa Cruz Biotechnologies, Santa Cruz, CA). Immuno-detection was carried out by a chemiluminescent method with a Phototope-HRP Western Detection Kit (Cell Signaling) and by an exposure to Hyperfilm-ECL (Amersham, Buckinghamshire, UK).

$R T$ - PCR. RNA was isolated from cultured cells using TRIzol reagent (Sigma). A first-strand cDNA was synthesized by reverse transcription of $5 \mu \mathrm{g}$ of total RNA in the presence of oligo(dt) and reverse transcriptase with a Superscript Preamplification System (Life Technologies). RT-PCR was performed to analyze mRNA expression for human VEGF in glioma cells. Primers for human VEGF (R\&D Systems) were used according to protocol indicated by the manufacturer. RT-PCR for $B$-actin was performed as an internal standard (33). The PCR reaction mixture contained $6 \mu 1$ of cDNA, $200 \mu \mathrm{M}$ of dNTPs, $0.8 \mu \mathrm{M}$ of primers, and 1.25 units of Taq DNA polymerase (Takara, Kyoto, Japan) in PCR buffer containing 1.5-2.5 mM MgCl 2 . The PCR cycle profile for 30 cycles were: denaturation at $94^{\circ} \mathrm{C}$ for $20 \mathrm{sec}$, annealing at $60^{\circ} \mathrm{C}$ for $30 \mathrm{sec}$, and extension at $72^{\circ} \mathrm{C}$ for $1 \mathrm{~min}$. The PCR products were electrophoresed in a $2 \%$ agarose gel containing ethidium bromide and enhanced for visual analysis with UV light.

\section{Results}

Increased levels of VEGF production from glioma cells under normoxic conditions. We compared the levels of VEGF secreted in the medium supplemented with $0.5 \%$ FBS for $48 \mathrm{~h}$ under a $5 \% \mathrm{CO}_{2}$-air mixture. Three of four glioma cell lines, 


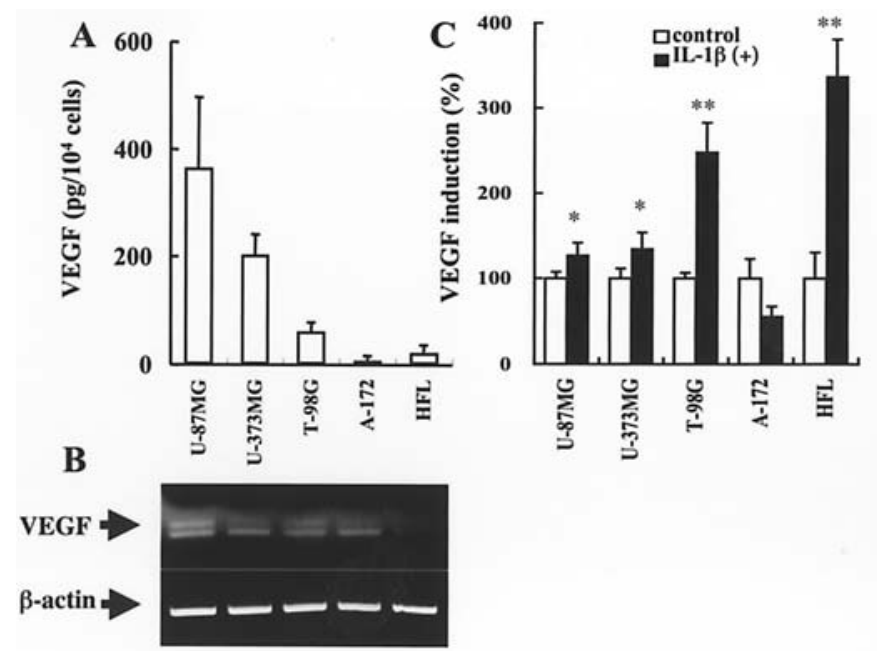

Figure 1. Secretion of VEGF from glioma cells. (A) Basal secretion of VEGF from glioma cells. Human glioma cells and fetal fibroblasts (HFL) were cultured in MEM with $0.5 \% \mathrm{FBS}$ for $48 \mathrm{~h}$ under a $5 \% \mathrm{CO}_{2}$-air mixture. The concentrations of VEGF secreted in the medium were measured with ELISA. (B) RT-PCR analysis for VEGF mRNA of glioma cells and HFL cultured in MEM with $0.5 \%$ FBS under $5 \% \mathrm{CO}_{2}$-air. RT-PCR for $B$-actin was used as an internal standard. (C) Stimulation of VEGF secretion by IL-1ß. Cells were incubated with MEM containing $0.5 \%$ FBS for $48 \mathrm{~h}$ in both the presence and absence of 500 units $/ \mathrm{ml}$ of IL-1ß. The inducible levels of VEGF were expressed as the percentages of basal levels of VEGF. Bar graphs show mean values with standard deviations (error bars) calculated from three or more separate experiments. IL-1ß significantly stimulated VEGF production in U373MG, U87 MG, T98G, and HFL. ${ }^{* *} \mathrm{P}<0.0001,{ }^{*} \mathrm{P}<0.01$ vs. without IL-1ß by unpaired t-test.

U87MG, U373MG, and T98G, secreted higher levels of VEGF protein than HFL (Fig. 1A). The levels of VEGF secretion were very low in A172 cells. The levels of VEGF secretion in the medium were 16, 9, and 3 times higher in U87MG, U373MG, and $\mathrm{T} 98 \mathrm{G}$, respectively, than those in HFL. RT-PCR analysis for VEGF mRNA showed that the signals for VEGF mRNA were consistent with the secretion of VEGF protein from glioma cell lines and HFL, except for A172 cells (Fig. 1B). The level of VEGF secretion in A172 was extremely low, even though the characteristic signals for VEGF mRNA were well defined. IL-1ß, 500 units/ml, significantly stimulated VEGF production in U373MG, U87MG, T98G, and HFL (Fig. 1C). T98G and HFL, in which the basal levels of VEGF secretion were relatively low, responded well to IL-1ß stimulation, with 2.5- and 3.4-fold increases in VEGF secretion, respectively. In contrast, in U87MG and U373MG cells, which secrete high levels of VEGF protein under steadystate conditions, levels of VEGF secretion in response to stimulation with IL-1B increased by only $27 \%$ and $35 \%$, respectively. A172 cells exhibited no increase in VEGF secretion in response to stimulation with IL-1ß.

No contribution of COX-2 to increased levels of VEGF secretion in glioma cells. We examined glioblastoma cell lines, U87MG, U373MG, T98G, which secrete high levels of VEGF, for the effects of non-selective (indomethacin) and selective (NS-398) COX-2 inhibitors on VEGF production. Both NS-398 and indomethacin failed to decrease VEGF production both with and without IL-1ß treatment (Fig. 2A). IL-1ß significantly stimulated the production of $\mathrm{PGE}_{2}$ in
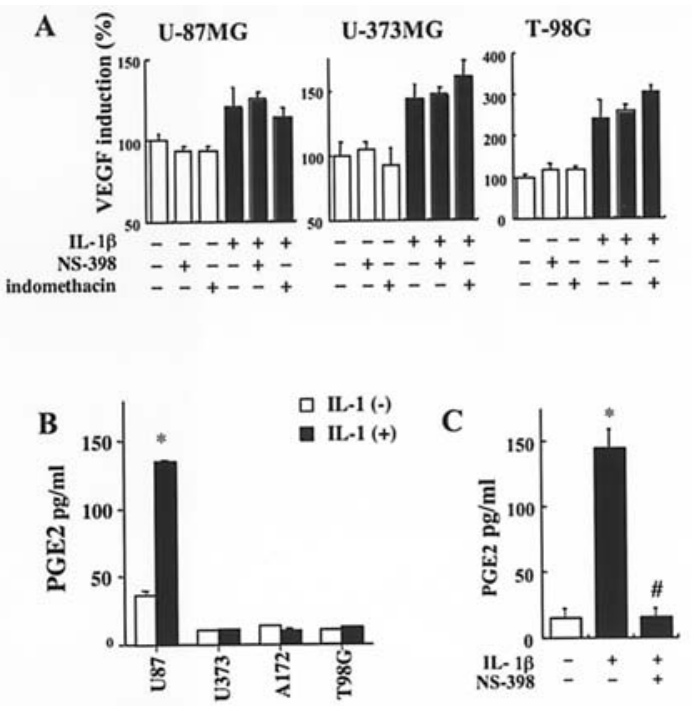

D

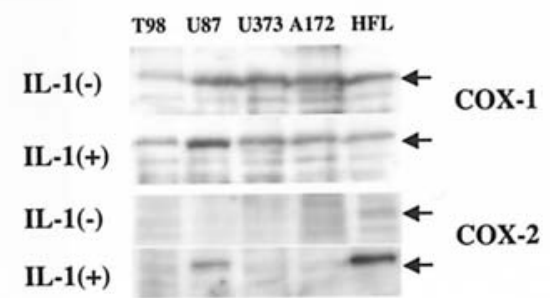

Figure 2. Effects of COX-2 inhibitors on VEGF secretion and COX-2 expression in glioma cells. (A) Effects of COX-2 inhibitors on VEGF secretion. Three glioblastoma cell lines, U87MG, U373MG, T98G, which secrete high levels of VEGF, were examined for the effects of non-selective (indomethacin) and selective COX-2 inhibitors (NS-398) on the secretion of VEGF. Cells were incubated with MEM containing $0.5 \%$ FBS for $48 \mathrm{~h}$ in both the presence and absence of 500 units/ml of IL-1B. NS-398 $(1 \mu \mathrm{M})$ and indomethacin $(1 \mu \mathrm{g} / \mathrm{ml})$ were added to the cultures. The concentrations of VEGF secreted in the medium were measured with ELISA. Both NS-398 and indomethacin failed to reduce the production of VEGF in both the presence and absence of IL-1ß. Bar graphs show mean values with standard deviations (error bars) calculated from three or more separate experiments. Results are normalized to control, set to $100 \%$. (B and C) $\mathrm{PGE}_{2}$ production in glioma cells. Cells were incubated with MEM containing 0.5\% FBS for $48 \mathrm{~h}$ in both the presence and absence of 500 units/ml of IL-1ß. PGE secreted in the medium was measured with an EIA. Bar graphs show mean values with standard deviations (error bars) calculated from three or more separate experiments. ${ }^{*} \mathrm{P}<0.001$ vs. control (B) ${ }^{*} \mathrm{P}<0.0001$ versus control $(\mathrm{C})$ ${ }^{\#} \mathrm{P}<0.0001$ vs. IL-1ß(+) by unpaired t-test. (D) Immunoblot for COX-1 and -2 . Cells were cultured in MEM with $0.5 \%$ FBS for $16 \mathrm{~h}$ in both the presence and absence of IL-1B. Cell extracts were run on $12.5 \%$ SDS polyacrylamide gels and transferred to Immobilon-P membranes. Immunodetection was carried out using a chemiluminescent method and by exposure to Hyperfilm-ECL.

U87MG cells but it did not in other glioma cell lines (Fig. 2B). NS-398 at a concentration of $1 \mu \mathrm{M}$ completely blocked the IL-1ß-induced production of $\mathrm{PGE}_{2}$ in U87MG cells (Fig. 2C). Neither glioma cell line exhibited positive immunoblot signals for COX-2 under steady-state conditions. Positive immunoblot signals for COX-2 were found only in IL-1ßstimulated U87MG and HFL cells (Fig. 2D). The results of immunoblot analysis were quite consistent with findings based on measurement of $\mathrm{PGE}_{2}$ production.

Activation of p38 MAPK and/or JNK contributes to increased levels of VEGF in glioma cells. We examined inhibitors of 

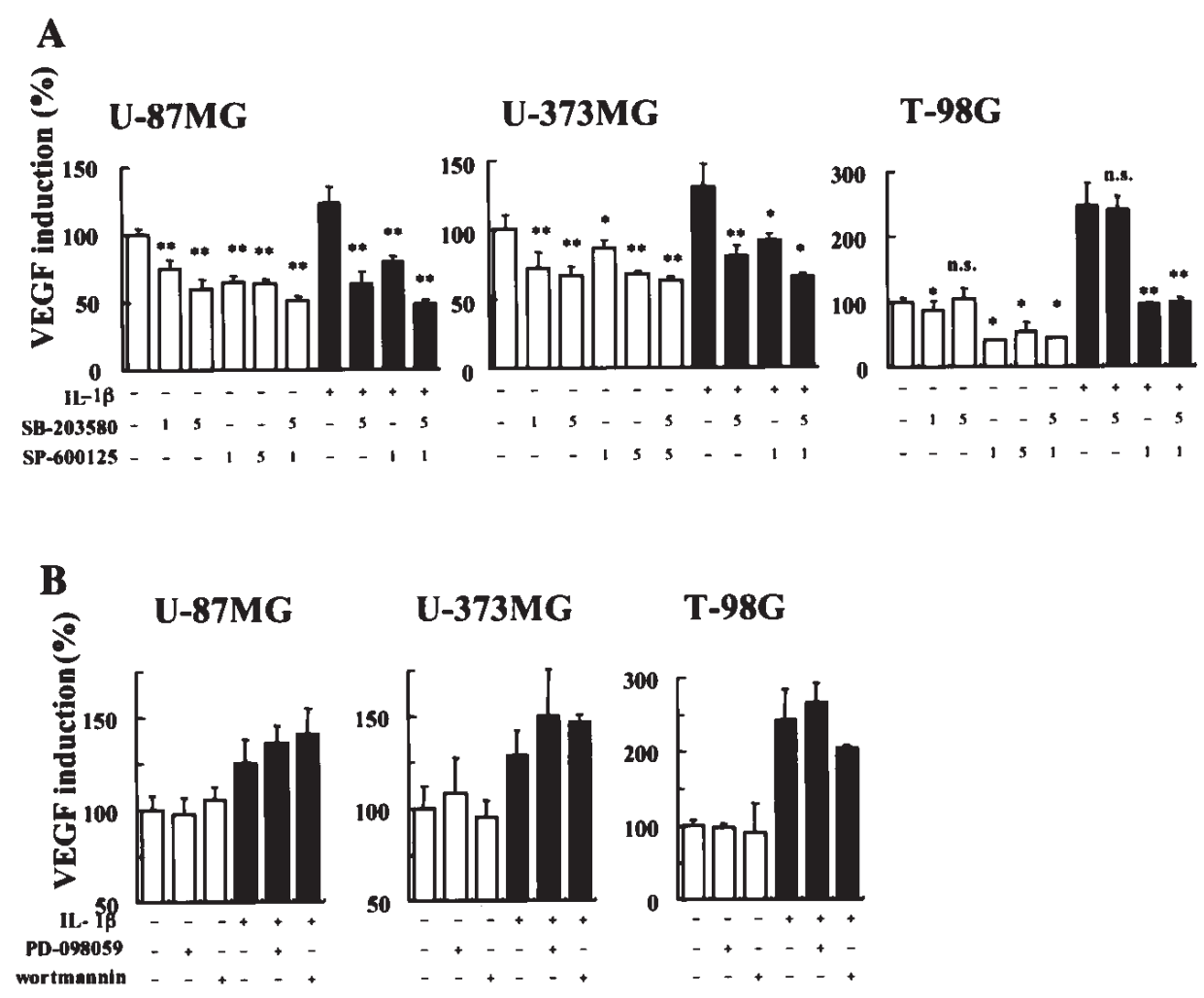

Figure 3. Effects of MAPK and phosphatidylinositol 3-kinase (PI3-K) inhibitors on VEGF secretion. (A) Effects of p38 MAPK and JNK inhibitors. Glioma cells were incubated both with and without SB-203580, a p38 MAPK inhibitor, and/or SP-600125, a JNK inhibitor, in MEM with 0.5\% FBS in both the presence and absence of IL-1B at concentrations of 500 units/ml. VEGF secreted in the medium was measured with ELISA. (B) Effects of inhibitors of ERK1/2 and PI3-K. Cells were incubated both with and without PD-98059 (10 $\mu \mathrm{M})$, an inhibitor of ERK1/2, or Wortmannin (100 nM), an inhibitor of PI3-K, in both the presence and absence of IL-1ß at concentrations of 500 units $/ \mathrm{ml}$. Bar graphs show mean values with standard deviations (error bars) calculated from three or more separate experiments. Results are normalized to control, set to $100 \%$. ${ }^{* *} \mathrm{P}<0.0001,{ }^{*} \mathrm{P}<0.01$ vs. without inhibitors by unpaired t-test.

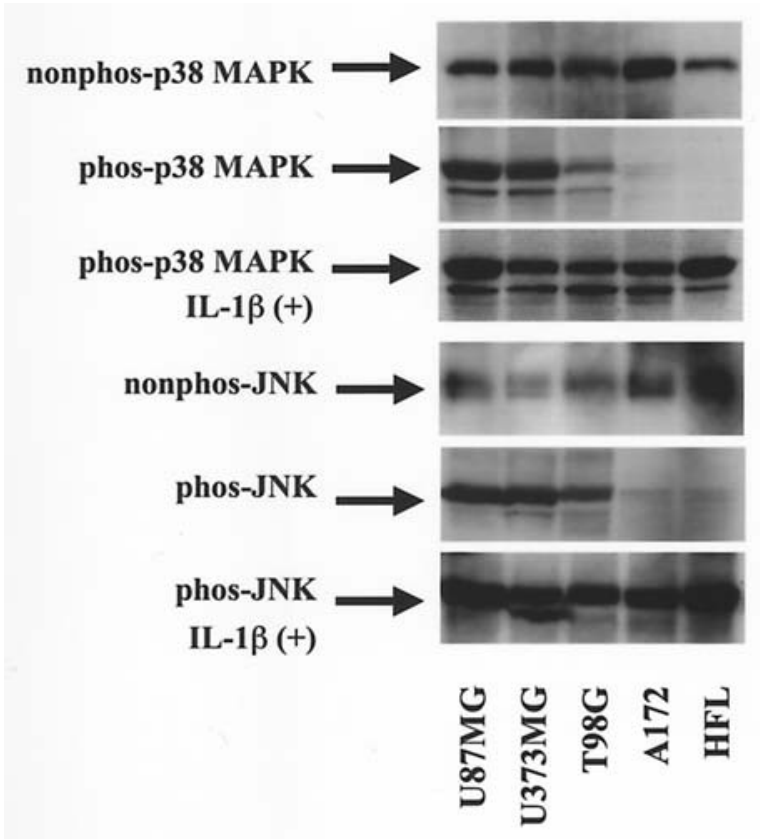

Figure 4. Immunoblots testing for phospho- or non-phospho-p38 MAPK and JNK. Glioma cells and HFL were incubated for $30 \mathrm{~min}$ with MEM containing $0.5 \%$ FBS both with and without IL-1ß at concentrations of 500 units $/ \mathrm{ml}$. Total cell extracts were run on $12.5 \%$ SDS polyacrylamide gels and transferred to Immobilon-P membranes. Immunodetection was carried out using a chemiluminescent method and by exposure to Hyperfilm-ECL.
MAPKs for effects on VEGF secretion in glioma cells. Both SB-203580, a p38 MAPK-specific inhibitor, and SP-600125, a JNK-specific inhibitor, significantly decreased the secretion of VEGF from U87MG and U373MG cells in both the presence and absence of IL-1ß (Fig. 3A). The combined use of both reagents resulted in additive inhibitory effects on VEGF secretion from these cells. In T98G cells, SP-600125 significantly decreased the secretion of VEGF in the presence and absence of IL-1ß, while SB-203580 had no measurable effects in either case. In contrast, neither PD-98059, an inhibitor of ERK1/2, nor Wortmannin, an inhibitor of PI3-K, had any effect on VEGF secretion in any glioma cell line (Fig. 3B).

We performed immunoblot tests for phospho- and nonphospho-p38 MAPK, and phospho- and non-phospho-JNK using specific antibodies (Fig. 4). We detected definite immunoreactive bands indicating phosphorylation of p38 MAPK and JNK in cell extracts from U87MG, U373MG, and T98G under steady-state conditions; and no immunoreactive bands were found in cell extracts from A172 or HFL. The immunoreactive bands indicating phospho-p38 MAPK under steady-state conditions were stronger in U87MG and U373MG than those in T98G, while those indicating phosphoJNK were similar in strength among the three glioma lines. The immunoreactive bands indicating phospho-JNK and phospho-p38 MAPK were well-defined in A172 and HFL when the cells were stimulated by IL-1ß. The effects of IL-1ß 

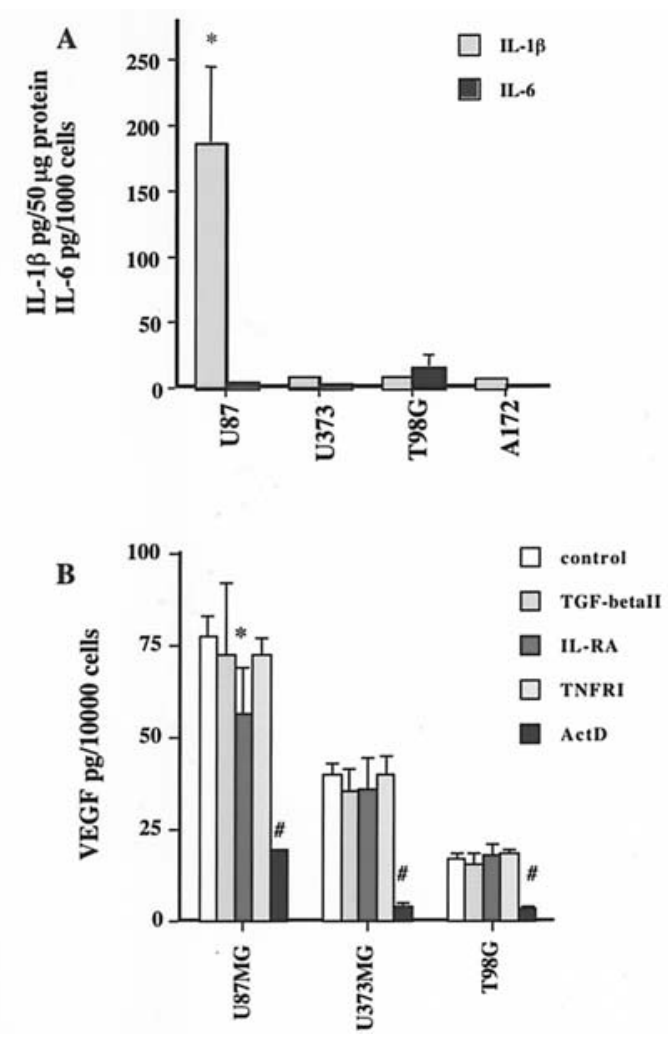

Figure 5. (A) Production of IL-1ß and IL-6 from glioma cells under steadystate conditions. Cells were incubated for $48 \mathrm{~h}$ with MEM containing $0.5 \%$ FBS. The concentrations of IL- $1 \beta$ in cell extracts and those of IL- 6 secreted into the medium were measured with ELISA. Bar graphs show mean values with standard deviations (error bars) calculated from three or more separate experiments. ${ }^{*} \mathrm{P}<0.001$ vs. U373MG, T98G, and A172 by unpaired t-test. (B) Effects of receptor antagonist and receptor blocking antibodies on the secretion of VEGF. Cells were cultured for $48 \mathrm{~h}$ in MEM with $0.5 \%$ FBS containing actinomycin D $(100 \mathrm{ng} / \mathrm{ml})$, IL-1 receptor antagonist $(100 \mathrm{ng} / \mathrm{ml})$, blocking antibodies to TNF receptor I $(10 \mu \mathrm{g} / \mathrm{ml})$, or TGFß-II receptor $(20 \mu \mathrm{g} / \mathrm{ml})$. The concentrations of VEGF in the medium were measured with ELISA. Bar graphs show mean values with standard deviations (error bars) calculated from three or more separate experiments. ${ }^{*} \mathrm{P}<0.02$ vs. control; ${ }^{\#} \mathrm{P}<0.001$ vs. control by unpaired t-test.

stimulation on immunoreactive band strength were not clear in U87MG and U373MG.

Intrinsic factors that can stimulate VEGF production via phosphorylation of MAPKs. Based on the present data that some glioma cells spontaneously secrete high levels of VEGF and exhibit constitutive phosphorylation of p38 MAPK and/or JNK, we hypothesized that some intrinsic factors of glioma cells could stimulate VEGF production via activation of $\mathrm{p} 38$ MAPK and/or JNK. It has been shown that JNK and p38 MAPK are strongly activated by cell stresses, bacterial lipopolysaccarides, IL-1, and TNF- $\alpha$ but are only weakly activated by mitogens, while ERKs are strongly activated by mitogens $(31,34,35)$. We examined glioma cells for the production of some cytokines under steady-state conditions and found that concentrations of IL- $1 \alpha$ and TNF- $\alpha$ in the medium and the cell extracts, and that of IL- $1 \beta$ in the medium, were below detectable limits in all the glioma cell lines (data not shown). The concentration of IL-1B in the cell extracts of U87MG was significantly higher than other glioma cell lines, while the levels of IL-6 were essentially the same among all four glioma cell lines (Fig. 5A).

We used IL-1 receptor antagonist, blocking antibodies to TNF receptor I and to TGFß-II receptor to reduce the production of VEGF from glioma cells under steady-state conditions (Fig. 5B). TGF- $\beta$ has been shown to stimulate VEGF production from cultured retinal pigment epithelial cells via activation of p38 MAPK (36). Actinomycin D was used to inhibit RNA synthesis and significantly blocked the production of VEGF from U87MG, U373MG, and T98G cell lines. IL-1 receptor antagonist significantly reduced the levels of VEGF production from U87MG but had little measurable effect on U373MG and T98G. Blocking antibodies to TNF receptor I and to TGFß-II receptor had no effect on VEGF production in any glioma cell line.

\section{Discussion}

We document in the present study the first evidence that glioma cells spontaneously secrete high levels of VEGF and exhibit constitutive phosphorylation of p38 MAPK and/or JNK. The basal levels of VEGF secretion were 16, 9, and 3 times higher in U87MG, U373MG, and T98G, respectively, compared with VEGF secretion levels in HFL. Experiments using inhibitors of MAPKs showed that inhibition of p38 MAPK and/or JNK suppressed both basal and IL-1stimulated secretion of VEGF in these cell lines. Constitutive phosphorylation of p38 MAPK and JNK were observed in these glioma cell lines. The effects of exogenous IL-1 on VEGF secretion were small in U87MG and U373MG and no enhanced phosphorylation of p38 MAPK and JNK was observed in these cells. These findings indicate that VEGF secretion was regulated via p38 MAPK and/or JNK pathway in these glioma cell lines under normoxic conditions. In A172, VEGF secretion was very low in both the presence and absence of IL-1ß, although expression of VEGF mRNA under steady-state conditions was quite clear and both p38 MAPK and JNK were activated by IL-1 stimulation. These effects may indicate the lack of a signal peptide necessary for VEGF secretion in A172 cells, or may be indicative of disorders in post-transcription regulation.

COX-2 is an inducible enzyme catalyzing the production of PGs from arachidonic acid at sites of inflammation $(34,38)$. Selective COX-2 inhibitors can block tumor angiogenesis via inhibition of VEGF expression $(21,23,24,42)$. High-grade glioma tissues exhibit high levels of COX-2 protein $(15,16,25-27,36)$. NS-398, a specific inhibitor of COX-2, significantly reduces the proliferation, growth, and migration of cultured human gliomas $(16,26)$. These lines of evidence have contributed to the hypothesis that COX-2mediated signaling pathways are closely related to increased levels of VEGF in gliomas. However, contrary to this hypothesis, our findings clearly indicate that COX-2 does not contribute to increased levels of VEGF in glioma cells under normoxic conditions.

Several studies have shown that the PI3-K/Akt pathway mediates hypoxia-induced VEGF expression in ras-transformed cells $(21,22)$. The PI3-K pathway and the ERK1/2 MAPK pathway are known to be downstream of Ras (29). Induction 
of VEGF in glioblastomas under ionized radiation (37) or acidic extracellular $\mathrm{pH}$ conditions (29) is reportedly mediated by activation of AP-1 via the ERK1/2 signaling pathway. The astrocytic tumors, regardless of grade, had the highest overall degree of ERK1/2. Particular to glioblastomas, microvascular hyperplasia and necrosis were associated with activation of ERK1/2 in tissues adjacent to tumor cells (38). However, the regulatory mechanism underlying the cytokineinduced expression of the VEGF gene has been shown to differ from that induced by hypoxia (19). Our findings that neither inhibitors of ERK1/2 nor PI3-K affect the basal or IL-1-stimulated secretion of VEGF from any glioma cell line support the notion that basal levels of VEGF secretion are regulated by mechanisms different from those induced by hypoxia.

The human VEGF promoter contains sequences corresponding to the HIF-1, AP-1, AP-2, and SP-1 binding sites. The HIF-1 and AP-1 binding sites have been shown to be essential for VEGF induction by hypoxia $(12,13)$. The AP-2 and SP-1 binding sites are located in promoter region 85-50 bp, which confers responsiveness to transforming growth factor- $\alpha$, IL-1, and TNF- $\alpha$ (19,39-41). Ryuto et al (19) indicated that four clustered SP-1 binding sites are important for both basal transcription and TNF- $\alpha$-induced transcription of the VEGF gene in glioma cells. In cardiac myocytes, activation of p38 MAPK and JNK may play a role in IL-1ß-mediated VEGF gene expression by transcriptional activation via SP-1 (40). Xiong et al (42) showed that heregulin- $\beta 1$ up-regulates VEGF secretion from breast cancer cell lines via the p38 MAPK pathway. These results are quite consistent with our data; glioma cells spontaneously secrete high levels of VEGF via constitutive activation of p38 MAPK and/or JNK, which are usually activated by cell stresses and some cytokines, including IL-1 and TNF- $\alpha$.

Malignant gliomas express high levels of VEGF not only in hypoxic regions, which are generally located near necrotic areas, but also at the extreme periphery of the tumor tissue where there is no hypoxia (7). Our results are in line with this observation and indicate the presence of a signaling pathway involved in VEGF secretion in malignant gliomas under normoxic condition that differs from the signaling pathways involved under hypoxic condition. The constitutive phosphorylation of p38 MAPK and/or JNK in glioma cells indicated the presence of intrinsic factors that could activate p38 MAPK and/or JNK. Upon this hypothesis, we identified a potential contribution of autocrine secretion of IL-1ß to the increased level of basal VEGF secretion only in U87MG. This may be due to an incomplete screening for the candidate intrinsic factors in the present study. Okajima et al (43) showed that in rat liver cells, VEGF expression was positively regulated by $\mathrm{p} 38$ MAPK in $v$-raf and $v$-myc transformed cells but not in parent or v-ras transformed cells. Because the expressed proto-oncogenes in glioblastomas are not found in ras but quite abundant in $m y c$ and raf (44), it is conceivable that raf and myc could contribute to the constitutive phosphorylation of p38 MAPK and/or JNK in malignant gliomas.

The role of tumor cells at the periphery of malignant gliomas is quite important because they are instrumental in the process of tumor invasion into the surrounding normal brain tissues. Tumor cells on the periphery of malignant gliomas interface with normal brain tissues, exhibit no hypoxia, need neovascularization, and interact with reactive astrocytes and infiltrating lymphocytes that have been shown to secrete various cytokines, including IL- 1 and TNF- $\alpha(45,46)$. The signaling pathways of VEGF secretion in malignant gliomas under normoxic condition involve p38 MAPK and/or JNK and may be distinct from those under hypoxia. These observations and findings will facilitate the creation of effective antiangiogenic approaches for currently incurable malignant gliomas.

\section{Acknowledgements}

We thank Dr Daniel Curewitz for reviewing the manuscript. This study was supported by a Grant-in-Aid for Scientific Research from the Ministry of Education, Science, Sports and Culture, Japan, and by a research grant from the president of Tokyo Medical and Dental University awarded in 2002.

\section{References}

1. Black PM: Brain tumor. Part 2. N Engl J Med 324: 1555-1564, 1991.

2. Wakimoto H, Aoyagi M, Nakayama T, Nagashima G, Yamamoto S, Tamaki M and Hirakawa K: Prognostic significance of Ki-67 labeling indices obtained using MIB-1 monoclonal antibody in patients with supratentorial astrocytomas. Cancer 77: 373-380, 1996.

3. Brat DJ and van Meir EG: Glomeruloid microvascular proliferation orchestrated by VPF/VEGF: a new world of angiogenesis research. Am J Pathol 158: 789-796, 2001.

4. Kleihues P, Burger PC, Collins VP, et al: Glioblastoma. In: Pathology and Genetics of Tumors of the Nervous System. Kleihues P and Cavenee WK (eds). IARC, Lyon, pp29-39, 2000.

5. Plate KH, Breier G, Weich HA and Risau W: Vascular endothelial growth factor is a potential tumour angiogenesis factor in human gliomas in vivo. Nature 359: 845-848, 1992.

6. Shweiki D, Itin A, Soffer D and Keshet E: Vascular endothelial growth factor induced by hypoxia may mediate hypoxiainitiated angiogenesis. Nature 359: 843-845, 1992.

7. Pietsch T, Valter MM, Wolf HK, von Deimling A, Huang HJ, Cavenee WK and Wiestler OD: Expression and distribution of vascular endothelial growth factor protein in human brain tumors. Acta Neuropathol 93: 109-117, 1997.

8. Cheng SY, Huang HJ, Nagane M, Ji XD, Wang D, Shih CC, Arap W, Huang CM and Cavenee WK: Suppression of glioblastoma angiogenicity and tumorigenicity by inhibition of endogenous expression of vascular endothelial growth factor. Proc Natl Acad Sci USA 93: 8502-8507, 1996.

9. Kim KJ, Li B, Winer J, Armanini M, Gillett N, Phillips HS and Ferrara N: Inhibition of vascular endothelial growth factorinduced angiogenesis suppresses tumour growth in vivo. Nature 362: 841-844, 1993

10. Millauer B, Shawver LK, Plate KH, Risau W and Ullrich A: Glioblastoma growth inhibited in vivo by a dominant-negative Flk-1 mutant. Nature 367: 576-579, 1994.

11. Saleh M, Stacker SA and Wilks AF: Inhibition of growth of C6 glioma cells in vivo by expression of antisense vascular endothelial growth factor sequence. Cancer Res 56: 393-401, 1996.

12. Damert A, Ikeda E and Risau W: Activator-protein-1 binding potentiates the hypoxia-induciblefactor-1-mediated hypoxiainduced transcriptional activation of vascular-endothelial growth factor expression in C6 glioma cells. Biochem J 327: 419-423, 1997.

13. Forsythe JA, Jiang BH, Iyer NV, Agani F, Leung SW, Koos RD and Semenza GL: Activation of vascular endothelial growth factor gene transcription by hypoxia-inducible factor 1 . Mol Cell Biol 16: 4604-4613, 1996.

14. Feldkamp MM, Lau N, Rak J, Kerbel RS and Guha A: Normoxic and hypoxic regulation of vascular endothelial growth factor (VEGF) by astrocytoma cells is mediated by Ras. Int $\mathbf{J}$ Cancer 81: 118-124, 1999.

15. Dunn IF, Heese O and Black PM: Growth factors in glioma angiogenesis: FGFs, PDGF, EGF, and TGFs. J Neurooncol 50: 121-137, 2000. 
16. Maity A, Pore N, Lee J, Solomon D and O'Rourke DM: Epidermal growth factor receptor transcriptionally up-regulates vascular endothelial growth factor expression in human glioblastoma cells via a pathway involving phosphatidylinositol 3'kinase and distinct from that induced by hypoxia. Cancer Res 60: 5879-5886, 2000.

17. Moriyama T, Kataoka H, Hamasuna R, Yokogami K, Uehara H, Kawano H, Goya T, Tsubouchi H, Koono M and Wakisaka S: Upregulation of vascular endothelial growth factor induced by hepatocyte growth factor/scatter factor stimulation in human glioma cells. Biochem Biophys Res Commun 249: 73-77, 1998.

18. Neufeld G, Cohen T, Gengrinovitch S and Poltorak Z: Vascular endothelial growth factor (VEGF) and its receptors. FASEB J 13: 9-22, 1999.

19. Ryuto M, Ono M, Izumi H, Yoshida S, Weich HA, Kohno K and Kuwano M: Induction of vascular endothelial growth factor by tumor necrosis factor alpha in human glioma cells. Possible roles of SP-1. J Biol Chem 271: 28220-28228, 1996.

20. Valter MM, Wiestler OD and Pietsch T: Differential control of VEGF synthesis and secretion in human glioma cells by IL-1 and EGF. Int J Dev Neurosci 17: 565-577, 1999.

21. Franke TF, Kaplan DR, Cantley LC and Toker A: Direct regulation of the Akt proto-oncogene product by phosphatidylinositol-3,4-bisphosphate. Science 275: 665-668, 1997.

22. Mazure NM, Chen EY, Laderoute KR and Giaccia AJ: Induction of vascular endothelial growth factor by hypoxia is modulated by a phosphatidylinositol 3-kinase/Akt signaling pathway in Ha-ras-transformed cells through a hypoxia inducible factor-1 transcriptional element. Blood 90: 33223331, 1997.

23. Majima M, Hayashi I, Muramatsu M, Katada J, Yamashina S and Katori M: Cyclo-oxygenase-2 enhances basic fibroblast growth factor-induced angiogenesis through induction of vascular endothelial growth factor in rat sponge implants. Br J Pharmacol 130: 641-649, 2000.

24. Tsujii M, Kawano S, Tsuji S, Sawaoka H, Hori M and DuBois RN: Cyclooxygenase regulates angiogenesis induced by colon cancer cells. Cell 93: 705-716, 1998.

25. Hara A and Okayasu I: Cyclooxygenase- 2 and inducible nitric oxide synthase expression in human astrocytic gliomas: correlation with angiogenesis and prognostic significance. Acta Neuropathol 108: 43-48, 2004.

26. Joki T, Heese O, Nikas DC, Bello L, Zhang J, Kraeft SK, Seyfried NT, Abe T, Chen LB, Carroll RS and Black PM: Expression of cyclooxygenase 2 (COX-2) in human glioma and in vitro inhibition by a specific COX-2 inhibitor, NS-398. Cancer Res 60: 4926-4931, 2000.

27. Shono T, Tofilon PJ, Bruner JM, Owolabi O and Lang FF: Cyclooxygenase- 2 expression in human gliomas: prognostic significance and molecular correlations. Cancer Res 61: 4375-4381, 2001.

28. Blumer KJ and Johnson GL: Diversity in function and regulation of MAP kinase pathways. Trends Biochem Sci 19: 236-240, 1994.

29. Tsuji F, Oki K, Senda T, Horiuchi M and Mita S: Effects of mitogen-activated protein kinase inhibitors or phosphodiesterase inhibitors on interleukin-1-induced cytokines production in synovium-derived cells. Immunol Lett 68: 275-279, 1999.

30. Xu L, Fukumura D and Jain RK: Acidic extracellular pH induces vascular endothelial growth factor (VEGF) in human glioblastoma cells via ERK1/2 MAPK signaling pathway: mechanism of low pH-induced VEGF. J Biol Chem 277: 11368-11374, 2002.

31. Cobb MH and Goldsmith EJ: How MAP kinases are regulated. J Biol Chem 270: 14843-14846, 1995.
32. Yamamoto K, Yamamoto M and Ooka H: Changes in negative surface charge of human diploid fibroblasts, TIG-1, during in vitro aging. Mech Ageing Dev 42: 183-195, 1988.

33. Duan L, Aoyagi M, Tamaki M, Nakagawa K, Nagashima G, Nagasaka Y, Ohno K, Yamamoto K and Hirakawa K: Sensitization of human malignant glioma cell lines to tumor necrosis factorinduced apoptosis by cisplatin. J Neurooncol 52: 23-36, 2001.

34. Marshall CJ: Specificity of receptor tyrosine kinase signaling: transient versus sustained extracellular signal-regulated kinase activation. Cell 80: 179-185, 1995.

35. Raingeaud J, Gupta S, Rogers JS, Dickens M, Han J, Ulevitch RJ and Davis RJ: Pro-inflammatory cytokines and environmental stress cause p38 mitogen-activated protein kinase activation by dual phosphorylation on tyrosine and threonine. J Biol Chem 270: 7420-7426, 1995.

36. Nagineni CN, Samuel W, Nagineni S, Pardhasaradhi K, Wiggert B, Detrick B and Hooks JJ: Transforming growth factorbeta induces expression of vascular endothelial growth factor in human retinal pigment epithelial cells: involvement of mitogenactivated protein kinases. J Cell Physiol 197: 453-462, 2003.

37. Mori K, Tani M, Kamata K, Kawamura H, Urata Y, Goto S, Kuwano M, Shibata S and Kondo T: Mitogen-activated protein kinase, ERK1/2, is essential for the induction of vascular endothelial growth factor by ionizing radiation mediated by activator protein-1 in human glioblastoma cells. Free Radic Res 33: 157-166, 2000.

38. Mandell JW, Hussaini IM, Zecevic M, Weber MJ and VandenBerg SR: In situ visualization of intratumor growth factor signaling: immunohistochemical localization of activated ERK/ MAP kinase in glial neoplasms. Am J Pathol 153: 1411-1423, 1998.

39. Gille J, Swerlick RA and Caughman SW: Transforming growth factor-alpha-induced transcriptional activation of the vascular permeability factor (VPF/VEGF) gene requires AP-2-dependent DNA binding and transactivation. EMBO J 16: 750-759, 1997.

40. Tanaka T, Kanai H, Sekiguchi K, Aihara Y, Yokoyama T, Arai M, Kanda T, Nagai R and Kurabayashi M: Induction of VEGF gene transcription by IL- 1 beta is mediated through ttress-activated MAP tinases and Sp1 sites in cardiac myocytes. J Mol Cell Cardiol 32: 1955-1967, 2000

41. Tischer E, Mitchell R, Hartman T, Silva M, Gospodarowicz D, Fiddes JC and Abraham JA: The human gene for vascular endothelial growth factor. Multiple protein forms are encoded through alternative exon splicing. J Biol Chem 266: 11947-11954, 1991.

42. Xiong S, Grijalva R, Zhang L, Nguyen NT, Pisters PW, Pollock RE and Yu D: Up-regulation of vascular endothelial growth factor in breast cancer cells by the heregulin-beta1activated p38 signaling pathway enhances endothelial cell migration. Cancer Res 61: 1727-1732, 2001.

43. Okajima E and Thorgeirsson UP: Different regulation of vascular endothelial growth factor expression by the ERK and p38 kinase pathways in v-ras, v-raf, and v-myc transformed cells. Biochem Biophys Res Commun 270: 108-111, 2000.

44. La Rocca RV, Rosenblum M, Westermark B and Israel MA: Patterns of proto-oncogene expression in human glioma cell lines. J Neurosci Res 24: 97-106, 1989.

45. Black KL, Chen K, Becker DP and Merrill JE: Inflammatory leukocytes associated with increased immunosuppression by glioblastoma. J Neurosurg 77: 120-126, 1992.

46. Chung IY and Benveniste EN: Tumor necrosis factor-alpha production by astrocytes. Induction by lipopolysaccharide, IFNgamma, and IL-1 beta. J Immunol 144: 2999-3007, 1990. 